\title{
XXXIV. Memoir upon the germination and fermentation of grains and forinaceous substances
}

\section{Messr. Vauquelin \& Messr. Fourcroy}

To cite this article: Messr. Vauquelin \& Messr. Fourcroy (1806) XXXIV. Memoir upon the germination and fermentation of grains and forinaceous substances, Philosophical Magazine Series 1, 25:99, 219-226, DOI: 10.1080/14786440608563437

To link to this article: http://dx.doi.org/10.1080/14786440608563437

曲 Published online: 18 May 2009.

Submit your article to this journal $\pi$

Џll Article views: 3

Q View related articles $\sqsubset$ 
assumed a polish by moulding itself on the glass into which it had been pressed. This result seems to bear some analogy to the substance called retinasphaltum described by Mr. Hatchett.

No. 30. is a piece of wood partially converted into coal by heat and compression. In some parts the substance entirely resembles pitch, being full of large and shining airholes; in others, the fibres of the word are still distinctly visible. The whole is jet black, and burns with a bright flame.

No. 21 . is a specimen of the substance, like wool, formed in several of these experiments by the exudation of the fusible metal through the barrels of iron; the metal, in a liquid state spouting to a considerable distance, and depositing this substance upon any obstacle opposed to the stream.

XXXIV. Memoir upon the Germination and Fermentation of Grains and Farinaceous Sulstances. By Messrs. VAUQUelin and Fourcroy.

[Continued from p. 182.]

\section{$\S$ IV. Analysis of Garden Beans.}

$T_{H E}$ infusion of the farina of garden beans, drawn clear off, and put into a phial well corked and completely filled, becomes troubled like milk, and makes an abundant deposit, which clears it up. I.eft in the phial for twenty days, it liberates no gas; it is acid, preserves the taste of beans, reddens turnsole, and is precipitated, by means of lime water, in transparent flakes: by the oxalate of ammonia it is precipitated abundantly; by ammonia, but slightly; by gall-nuts, in flakes like wine lees; by the nitrates of mercury and silver, in yellowish white; and by the prussiate of potash, in green flakes which become blue.

The spontaneous deposit becomes transparent upon drying, and burns like horn.

The same infusion, put into.a large bottle about threefourths empty, acts in the same manner as at first; it diminishes 
minishes the volume of air, which afterwards contains a fifth part of carbonic acid, and the residue of which is then formed of 97.5 of azotic gas and of 2.5 of oxygen gas. The liquor assumes a smell slightly putrid, without acidity; it precipitates lime water, gall-nuts, \&c. \&c.

The precipitate formed by lime water is of a purple colour, which blackens on drying; it yields ammonia on being burnt, and leaves a gray cinder, soluble in the muriatic acid with effervescence, from which ammonia precipitates it in gelatinous flakes, and the prussiate of potash in white. Thus this precipitate contains an animal matter-phosphate of lime and phosphate of iron, besides the phosphate of potash remarked by $M$. Saussure junior.

We burned some dry garden beans to ashes in a platina crucible. The taste of these ashes was alkaline and caustic; they contained potash and phosphates of lime, magnesia, and iron, which the nitric acid dissolves.

Garden beans also contain starch, an animal matter, phosphates of lime, magnesia, potash, iron, and free potash. No sugar is found in it, at least not in any appretiable quantity.

The tunic, or coat of these beans, contains tannin in abundance.

This analysis explains, Ist, why beans putrefy so easily, and become infectious: 2dly, why they are so nourishing, and susceptible of filling the place of all other food: 3dly, why, when cooked with the skins on, they are better preserved : and, 4thly, why this article yields at once the aliment, the basis, and the materials proper to form and colour the blood, and to nourish the bones.

\section{$\S \mathrm{V}$. Analysis of Lentils.}

The farina of lentils, macerated in water, spreads the smell of this green leguminous herb; after an hour's maceration the water does not become clear, except after two filtrations; its taste is weak and nauseous; it is not acid; it precipitates abundantly by gall-nuts and the oxymuriatic acid, as well as by sulphate of iron: lime water renders it milky. It becomes troubled spontaneously, and becomes speedily milky; 
milky; the alkalis render it clear by making it yellow; the acids, which clear it at first, put into it afterwards in excess, precipitate it strongly. This seems to indicate that the liquor owes its limpidity to the alkali which absorbs the acid, either spontaneous or added.

The infusion grows frothy and coagulates at a boiling heat; when filtered, it precipitates, but less abundantly, by the re-agents indicated.

Upon inclosing, at a low temperature, this infusion, already troubled, in two flasks, the one filled and the other threefourths empty, with Woolf's tubes, we saw it become clear, and deposit white flakes after some hours. We did not observe, after a few days, any apparent change of the liquer, disengagement of gas, or absorption of air ; the water was acescent, and the air above it contained a little carbonic acid . gas.

Lime hindered the spontaneous precipitation of the infusion until it was saturated by its fermented acid.

Fifteen parts of alcohol, digested several times upon the coarser farina of lentils, was coloured a greenish yellow, and acquired a bitter and sharp taste. When distilled, the produce yielded a very strong smell of vanilla, which water caused to disappear by changing it into another very disagreeable. The residue of this distillation is yellowish green; a thick green oil floats at the surface; the liquor is thick and gluey, of a saponaceous smell, and of a rancid taste; the acids and lime water coagulate it like a water of soap. Sulphuric acid, by decomposing it, collects on its surface a rancid greenish oil of the smell of populentm: upon evaporating the water a black residue is obtained of a saline appearance, but in such a small quantity that we could not determine the nature of it.

Whole lentils, macerated in double their weight of water, yield, after twenty-four hours, a greenish yellow infusion of an astringent taste. Water precipitates a strong size, sulphate of iron a fine blue, and acetate of lead a yellowish white, without reddening the blue colours : lentils, stripped of their skin, afford no traces of tannin, which seem only to belong to this envelope. 
When cleaned completely by means of water, the skins of these lentils macerated in alcohol gave it a fine yellowish green colour; spontaneously evaporated, this alcohol deposited green flakes and a crust of the same colour; it blackened the solution of iron. After this double treatment, these skins are dry and arid. They furnished upon distillation a good deal of oil, the smell and taste of which resembled tobacco smoke; the water of the distillation is acid, but yields ammonia by means of potash. Thus, besides their feculent matter, lentils contain a kind of albumen and a little green oil : their bark contains tannin and more oil.

\section{§VI. Analysis of the Farina of Lupines.}

1st, This farina is yellow and very bitter; when exposed to the fire, it exhales an animal odour.

ed, Distilled in a retort it yields three-twelfths of charcoal, nearly seven-twelfths of a foetid red oil, a twelfth of phlegm, and a twelfth of crystallized carbonate of ammonia. The water contains a little ammoniacal acetate. We find in the charcoal phosphate of potash, because its watery ley precipitates calcareous phosphate by the addition of lime water. We also find in the ashes of the burned farina of lupines, phosphates of lime, magnesia, and iron.

$3 d$, It colours alcohol yellow, and renders it bitter; the latter, spontancously evaporated, leaves a yellow, thick, and very bitter oil, forming a-seventh of the weight of the farina, which almost entirely dissipates upon burning coals, with the smell of fat oil.

4 th, The farina of lupines gives water a yellow colour, a bitter taste, and a frothy quality, without rendering it either acid or alkaline. This water precipitates white Hakes by the oxymuriatic acid; a purple coagulum by infusion of galls*; very abundant white flakes by the nitrates of mercury and silver, and the acetate of lead: there are a few muriates, not soluble by the nitric acid, in the latter precipitates. It yields also yellowish flakes by means of lime water, and a white powder of calcareous oxalate by means of the ammoniacal oxalate.

- M. Vauquelin attributes this colour to a little phosphate of iron. 
5th, The farina, treated twice successively by alcohol and water, is dissolved almost entirely afterwards in the concentrated acetic acid: this solution, by means of the infusion of galls, precipitates in abundance oxymuriatic acid, ammonia, and mercury.

6th, Diluted in water, and exposed to a gentle heat, the farina of lupine ferments, exhales carbonic acid, forms acetic acid, without any vestige of alcohol, and soon putrefies, exhaling a foetid odour.

It results from this analysis that the farina of lupines contains :

1st, A bitter and coloured oil, to the amount of a seventh, which communicates its properties to the whole mass.

2d, A vegeto-animal matter, soluble in plenty of water, and much more so in the acetic acid. It is this which furnishes oil and ammonia upon distillation, and which gives to the watery infusion all its properties of precipitation.

3d, Phosphates of lime and magnesia aburdant enough, and small quantities of phosphates of potash and iron.

4th, It contains neither starch nor sugar, and, on this account, differs from the other leguminous farinas.

\section{$\S$ VII. Upon the Germination of Leguminous Seeds.}

1 st, In Floreal of the year 12, we placed lentils and garden beans, freed from their husks, under a bell-glass full of atmospheric air, placed upon water, and in a capsule of porcelain. The former germinated three or four.days afterwards ; their radicles were very long, and the plumules very perceptible; twelve days afterwards their height was three centimetrés; their leaves were displayed. The beans had no sign of germination at all ; their radicles, however, were lengthened, without the plumule having made any progress. They began to turn mouldy, and at this period the experiment was stopped. The air of the bell-glass extinguished a taper and precipitated lime water, although it still allowed phosphorus to burn a little.

$2 \mathrm{~d}$, The same seeds, placed at the same period under a bell-glass full of hydrogen gas placed upon water, presented no appearance of germination, not even a development of 
the radicle; they preserved their freshness and consistence $;$ the beans did not turn mouldy. The hydrogen gas contained carbonic acid entirely formed by the seeds, which afterwards germinated in the open air. Thus hydrogen gas does not favour germination; but it does not take away from seeds the property of germinating.

3d, Garden beans macerated in water, deprived of their skin, and afterwards replunged in this liquid, did not germinate in the course of eight days; the water became sour, and assumed the smell of sour cheese.

4 th, The water sharpened with a little oxymuriatic acid had no more success. The lentils, treated in the same manner, did not germinate. These seeds no longer germinated in the air ; those which had been plunged in water, on the contrary, germinated in the air.

5 th, The same seeds peeled, covered with a little water, enough, however, to be deprived of the contact of the air, putrefied instead of germinating. When only moistened, however, and without being deprived of this contact, they germinated very well and sent out coloured leaves, although in the shade.

We may conclude from these experiments that the influence of the air is requisite for germination, as has been already announced by $M$. de Saussure.

\section{$\S$ VIII. Experiments upon the Fermentation of Grains.}

1st, Two pounds of ground germinated barley, placed with six pounds of water heated to $55^{\circ}\left(131^{\circ} \mathrm{Fahr}\right.$.) in a matrass furnished with a crooked tube, fermented in four hours in a heat of $22^{\circ}\left(72^{\circ} \mathrm{Fabr}\right.$.) The fermentation continued 36 hours. The gas disengaged and collected was partly formed of carbonic acid and partly of hydrogen gas pure enough. Six days afterwards this barley was distilled, from which a product was obtained equal at least to one-third of the water employed. This prorluce, heavier than water, was acid and empyreumatic. This acidity demonstrates the conversion of alcohol into acetous acid. The liquor, which was saccharine at the period of distillation, was no longer so afterwards. 
2d, The same ground and germinated barley, but deprived of its bran by bolting, was treated in the same manner as in the first experiment; it fermented with the same appearances, and yielded an equal part of carbonic acid gas and hydrogen gas. Thus the bran was not the source of the latter gas, as at first supposed.

3d, Brewers' mash, exposed in the same apparatus to the same temperature of 22 degrees, fermented more quickly with a more rapid effervescence, and its gas was merely carbonic acid, without hydrogen gas. Thus the latter depends upon the farina mixed with flour.

4 th, The farina of germinated barley, with water, exposed in the matrass to a temperature of $15^{\circ}\left(59^{\circ}\right.$ of $F$.) did not ferment until the end of five hours; and its gas was condensed by potash. Upon raising the temperature to 22 degrees, there came off a mixture of gas not soluble and inflammable, the proportion of which was soon equal to that of the earbonic acid. Thus it is necessary that there should be a heat of upwards of $20^{\circ}\left(68^{\circ}\right.$ of $\mathrm{F}$.) before there can be any liberation of hydrogen gas in the farina of barley which is fermenting.

5 th, Six pounds of ground barley, not germinated, treated at three several times with twelve pounds of warm alcohol, furnished one ounce two drachms of pure sugar; while six pounds of germinated barley, treated in the same mannet, yielded four ounces and two drachms, or about 5 per cent; which is four times what the barley contained previous to germination. Thus, germination forms sugar, as we have announced.

$6 \mathrm{th}$, We put 24 pounds of farina of barley, not germinated, into a tub with seven times its weight of hot water at $70^{\circ}\left(158^{\circ}\right.$ of F. $)$ and four pounds of mild beer yeast. Fermentation immediately commenced with great violence, and continued seven days. The liquor submitted to distillation, with the husks, yielded sine litres of a weak and empyreumatic liquid, which, being passed again through the still, furnished 16 decilitres of an alcohol at 16 degrees, which comes to nine decilitres at 40 degrees. These nine decilitres, weighVol, 25. No. 99. Aug. 3806. P ing 
ing 23 ounces, and 24 pounds of barley not germinated, containing only five ounces of sugar, it follows, that four times more alcohol was formed than there was sugar in this farina. Lavoisier, however, asserts that 100 pounds of sugar furnish only 58 pounds of alcohol.

7 th, Twenty-four pounds of germinated and ground barley, made to ferment under the same circumstances as barley not germinated, presented the same phænomena, and only varied in their products. There were two litres 0.3 of alcohol at 40 degrees, which makes five pounds of alcohol for a quintal of barley, or three times more alcohol than there was sugar; and this answers to the produce of barley not germinated.

It must be concluded from these results that it is some other substance than sugar which is converted into alcohol, although sugar is indispensable to its production and to the establishment of fermentation.

8th, Two pounds of farina of bolted wheat, mixed with six pounds of water at $60^{\circ}\left(140^{\circ} \mathrm{F}\right.$.) remained six hours without motion. The next day, after having remarked the swelling of the mass, wo placed the matrass upon a sand-bath a little heated, and added water to favour the disengagement of the gas. We obtained hydrogen gas twice larger in volume than carbonic acid. The vessel, having been taken off the sarid-bath, the temperature having decreased to $14^{\circ}$ $\left(57^{\circ} \mathrm{F}\right.$.) the fermentation all at once stopped. The liquid, when submitted to distillation, did not yield alcohol, but an acid liquor.

The farina of wheat, therefore, does not form alcohol by fermentation: yeast is indispensable for this fermentation, although it does not enter into the composition of alcohol; by accelerating the alcoholic fermentation, it opposes the formation of vinegar. When, on the contrary, the fermentation is very slow, the alcohol becomes acetous in proportion as it is formed; perhaps even then sugar and the other fermenting substances pass into the acid state without alcoholizing. 